\title{
Emerging Adults' Outlook on the Future in the Midst of COVID-19: The Role of Personality Profiles
}

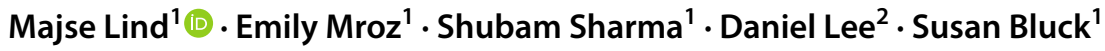

Accepted: 15 January 2022 / Published online: 9 February 2022

(c) The Author(s), under exclusive licence to Springer Science+Business Media, LLC, part of Springer Nature 2022

\begin{abstract}
Classic lifespan developmental theory describes emerging adulthood and the transition to adulthood as important periods for thinking about one's future life trajectory. Today, youth are facing far-reaching changes to daily life due to COVID-19. This may have negative effects on their future outlook, and the extent of such effects may be related to personality. This study examined emerging adults' $\left(N=195, M_{\text {age }}=20.58, S D=3.98\right)$ multidimensional personality profiles in relation to the extent that they hold a positive outlook on their future at the outset of the COVID-19 pandemic. Quantitative and brief narrative measures of future outlook were collected. Hierarchical cluster analysis and Latent Profile Analysis revealed two clear personality profiles, labeled Reflectors $(n=106)$ and Forgers $(n=89)$. Forgers demonstrated robust personality characteristics indicative of psychologically 'pushing forward' through pandemic-related challenges. Reflectors demonstrated more pandemic reactivity including higher stress but also more psychological integration of the pandemic experience into their sense of self. In terms of future outlook, Forgers reported a positive and expansive outlook on the future across multiple measures. In contrast, Reflectors held more negative, restricted views of what future life might hold. Results are discussed in terms of the role of multi-level personality in dictating emerging adults' future perspectives in the wake of life challenges. Ideas are presented about how to best support young people as they transition into the future, into adulthood, while grappling with the challenges of the pandemic.
\end{abstract}

Keywords COVID-19 $\cdot$ Future outlook $\cdot$ Transition to adulthood $\cdot$ Emerging adults $\cdot$ Personality

\section{Introduction}

Emerging adulthood is characterized by developmental tasks necessary for transitioning to adulthood and life ahead (Arnett, 2007). One such task is holding an open, optimistic

Majse Lind

mlind@ufl.edu; mlind@hum.aau.dk

Emily Mroz

elmroz@ufl.edu

Shubam Sharma

shubam.sharma@ufl.edu

Daniel Lee

dlee089@ucr.edu

Susan Bluck

bluck@ufl.edu

1 Department of Psychology, University of Florida, Gainesville, FL 32611, USA

2 Department of Psychology, University of California, Riverside, CA 92521, USA outlook on the future (Carstensen et al., 1999). The COVID19 pandemic has wreaked considerable havoc worldwide for people of all ages. In particular, emerging adults in the US have been confronted with substantial declines in work opportunities, strains on social relationships, and erosion of personal well-being (Kassid, 2020; Wang et al., 2020). Maintaining a positive view on their trajectory into adulthood, and their future life ahead, has become more complex for emerging adults in the context of the pandemic. Though this may be somewhat true for all young adults, we suggest that differing personality profiles may show variations in the extent to which future outlook is limited under these circumstances.

Below, we describe emerging adulthood as the life phase in which individuals normatively have the most expansive outlook on their future and how this open view of the future is central to positive development. Next, we argue that life during the COVID-19 pandemic may be influencing emerging adults' views of their future. Our conceptualization and operationalization of personality are then presented, inspired 
by McAdams' (2013) integrated multi-level personality framework. Analyses focus on identifying personality profiles and then examining how those are related to sustaining varying future outlooks despite the pandemic.

\section{Normative Transition to Adulthood: The Future Awaits Me}

Emerging adulthood refers to individuals aged 18 to 25 , largely in industrialized societies, who are pursuing distinct developmental tasks in preparation for adulthood (e.g., higher education, career development; Arnett, 2013). Given their early phase in the lifespan, emerging adults are understandably focused on growth, gains, and their potential for future accomplishments (Baltes, 1997; Erikson, 1968). Though there are exceptions, most emerging adults see their future as relatively bright (Berntsen \& Rubin, 2004) and as temporally expansive in comparison to older age groups (Carstensen et al., 2020; Demiray \& Bluck, 2014). Across the lifespan, perception of the time ahead in one's life guides individuals' goals (e.g., socioemotional selectivity theory, Carstensen et al., 1999) as well as their behaviors and attitudes (Andre et al., 2018). As such, emerging adults see an open vista ahead of them and are motivated to seize opportunities to build a positive future (e.g., establishing a work life, finding a life partner; Berntsen \& Rubin, 2004).

\section{COVID-19: Disruptions to Future Outlook}

The COVID-19 pandemic continues to have an unsettling influence on future outlook in emerging adulthood, and with good reason. The United Nations (i.e., UN) labor chief Guy Ryder described young adults as the lockdown generation (UN News, May 27, 2020): they are facing disruptions to work opportunities, social relationships (Kassid, 2020), and personal well-being (Shanahan et al., 2020; Wang et al., 2020). In keeping with the global trend (Zhang, 2020), the US has seen a worrying increase in unemployment among young adults (from 7.5 to 29\%; February to April, 2020; Tidey, 2020). The pandemic has also brought social challenges. Universities and businesses moving online or closing repeatedly over time have resulted in many emerging adults abruptly moving home to live with parents on one or more occasions (Cohn, 2020). Emerging adults' social lives also transitioned: in-person contact with family increased while in-person interaction with same-aged peers decreased. For some, dating was also put on hold or conducted solely virtually (Segran, 2020). This could potentially delay the development of romantic relationships and beginning to plan a family (Pohle, 2020). Along with these work and relationship challenges, pandemic-related stress continues to affect personal well-being (Gonzalez-Sanguino et al.,
2020). Throughout the pandemic, emerging adults have reported higher levels of loneliness as compared to older adults (Luchetti et al., 2020).

In sum, changes in life due to the pandemic have created uncertainty about the future for emerging adults as they navigate their way into adulthood. In this life phase that is normatively associated with planning for the best possible future for oneself, individuals may be struggling to maintain an expansive and optimistic future outlook. Unlike middle-aged or older adults, who often have faced a variety of significant life events and lived through historical periods of hardship (Lind et al., 2020), emerging adults typically have few life experiences to guide them through uncertain historical times. Given younger adults' lack of relevant life experiences to draw on, we suggest that personality may be a crucial source of strength (see also Neff \& McGehee, 2010) for offsetting the negative effects of pandemic-related challenges in this life phase. As such, we explored whether distinct personality profiles were differentially related to maintaining a positive future outlook.

\section{Multi-level Personality: Examining Profiles during the COVID-19 Pandemic}

The current study was guided by McAdams' (2013) holistic, three-level framework to identify the most relevant set of personality characteristics to be examined in the profiles. The base level of McAdams' model is the self as actor, comprised of personality traits (i.e., Big Five; Costa \& McCrae, 1992; Costa et al., 2019) and decontextualized behavioral tendencies (Dunlop et al., 2015). At this level, positive functioning in the face of the pandemic might manifest as desirable traits (e.g., elevated extraversion, lower neuroticism). Such traits have been related to higher subjective well-being and adaptive functioning in the face of challenges (e.g., Richards \& Huppert, 2011).

The next level of the framework is the self as agent, constituted by context-specific motivational goals and attitudes (e.g., McAdams, 2013). Here, positive functioning during the COVID-19 pandemic can be operationalized in terms of individuals' responses to stress (i.e., adaptation to difficulties using available resources; Luthar, 2006), ability to show a sense of gratitude despite loss (McCullough et al., 2004), and extent of internal locus of control (Krampe et al., 2021).

The final personality level in McAdams' (2013) framework is the self as author. This refers to considering one's identity as a developing life story. In late adolescence, individuals begin to integrate their past into a biographical life story (Habermas \& Bluck, 2000) which also includes envisioning their future (McAdams, 2013). At this level, positive functioning during the pandemic may involve, for example, the ability to integrate stressful experiences (i.e., the onset of the pandemic itself) into one's larger life story (Holland 
et al., 2016) and the ability to maintain one's sense of selfcontinuity, so as to avoid struggling with identity (Bluck \& Alea, 2008).

\section{The Current Study}

Making a successful transition from late adolescence into adulthood has major implications for ongoing well-being, including how one's outlook on the future promotes goalsetting and goal pursuit (e.g., Carstensen et al., 1999; 2020). We have argued that life challenges resulting from the COVID-19 pandemic may threaten emerging adults' outlooks on their future but that the extent of this disruption may depend on their personality. The current study's aims were to identify (1) distinct profiles of personality among emerging adults (aged $\sim 18-22$ ), and (2) how obtained personality profiles were related to individuals' outlooks on their future during the COVID-19 pandemic. To create a comprehensive set of variables from which to create personality profiles, the current research includes characteristics drawn from all three levels of McAdams' (2013) framework. To comprehensively capture individuals' views on their life ahead, a multiple-measurement approach to assessing future outlook was taken. This included quantitative assessments of individuals' future life scripts, reports of future time perspective, prospective search for meaning in the life onward, as well as an open-ended future narrative for the year ahead that was content coded for affective tone.

\section{Data Collection Context: Onset of the COVID-19 Pandemic}

The COVID-19 pandemic, with consequent effects on everyday life, manifests differently for different people in the various parts of the US and the world. To orient the reader to the historical context in which the current data were collected, we provide brief information on policies, infection trends, and pandemic guidelines being publicized at that time. The study data were collected during the first phase of the global pandemic, March and April, 2020, in the Southeastern US. In mid-March, 2020, the World Health Organization (WHO) labeled this health crisis a pandemic (WHO, Centers for Disease Control and Prevention, 2020). This announcement triggered safety measures and protocols as well as intense daily news coverage across the US. The university at which the data were collected went completely online March 17, 2020 out of concern for student and faculty health (ufl.edu). By late March, 2020, the WHO reported over 500,000 confirmed cases of COVID-19 worldwide (WHO), including nearly 70,000 cases in the US, and about 4000 cases in the region of the US where the study took place (Floridahealth. gov) (Florida Department of Health, 2020). The WHO had reported over 23,000 deaths due to COVID-19 worldwide (WHO) (World Health Organization, 2020), including nearly
1000 in the US and about 50 in the region of the US where the study took place (MySunCoast). During this time, best practices for reduced exposure to COVID-19 were publicized through the university, the community, and national media (e.g., coronavirus.ufl.edu/updates). These included healthy hygiene (e.g., hand washing and use of disinfectant, cleaning surfaces frequently) and maintaining social distancing (now referred to as physical distancing; Campbell et al., 2020) through identifying a social bubble and interacting with others at a distance of six feet. Individuals were, in general, advised to stay home if possible and particularly if symptoms were detected. By April, 2020, the WHO and US Centers for Disease Control and Prevention (CDC) began to recommend mask wearing for all individuals when in public spaces (CDC).

\section{Method}

\section{Participants}

This study was approved by the Institutional Review Board of the University where this study took place. Participants (original $N=231$ ) were excluded if they incorrectly answered more than one item embedded to ensure that they were paying attention (e.g., answer "Mostly Agree" for this item; $n=8)$ or did not finish the study $(n=15)$. The final sample comprised 208 American late adolescent-emerging adults $\left(M_{\text {age }}=20.58, S D=3.98 ; 66.3 \%\right.$ female $)$. Reported demographics reflect the region and were $72.1 \%$ White, 14.4\% Asian American, 5.8\% Black, 2.4\% Multiracial. The vast majority (96.6\%) of participants were full-time students (not part-time). Some participants also maintained jobs outside of school: 11 (4.8\%) were full-time employees and 59 (28.6\%) were part-time employees. Participants were recruited through university psychology courses and received course credit.

\section{Procedure}

This online study involved completing quantitative measures, as well as responding to a brief open-ended narrative prompt concerning participants' views of their life in the year ahead. Important to the goal of capturing responses specific to the pandemic, instructions for all measures (unless otherwise noted) stated, while completing this, please consider how you have been feeling in relation to the COVID-19 pandemic. After completing Informed Consent and responding to questions about personal background and COVID-19-related stress, measures related to the three levels of personality (i.e., actor, agent, author; McAdams, 2013) were completed. To assess emerging adults' views of their future, a multi-measure approach 
was taken (i.e., assessment of future life scripts, future time perspective, prospective search for life's meaning, and an open-ended narrative envisioning the year ahead). For the future narrative, participants were instructed to respond to the following prompt: "In the wake of COVID19, how do you see your future over the coming year (e.g., what events/experiences may happen, when may they happen, and with whom)? Please provide specific insights about what you may be thinking, saying, feeling, or doing over the coming year."

\section{Measures}

Measures are presented as grouped into variable categories: demographics and background, personality profile constructs (i.e., pandemic stress; personality levels of actor, agent, and author), and variables representing future outlook. The personality profile constructs were chosen to encompass a variety of factors that contribute to psychosocial functioning in daily life and may be particularly relevant in facing challenging events. Challenges, such as the onset of the COVID-19 pandemic, are responded to in complex ways. As such, it was expected that examining psychosocial constructs at this higher-order level (i.e., a personality profile approach) would be most robust. Note that during data collection, measures were administered in the following order: perceived stress, integration of pandemic experience, future time perspective, Big 5 inventory, prospective search for meaning, demographics, thinking about life experiences, open-ended brief narrative prompt for future year ahead, life script events, locus of control, resilience, and gratitude.

\section{Demographics and Background}

Demographics Participants reported demographic information including their age, gender, and race. They also reported religious affiliation, political affiliation, neighborhood characteristics (i.e., urban, rural, suburban), and personal health (i.e., compared to other people my age, I believe my health to be (select one) on a Likert Scale from 1=very good to $6=$ very poor).

\section{Pandemic Stress}

Perceived Stress Participants completed the 10-item Perceived Stress Scale (Cohen et al., 1983), indicating how often from 0 (never) to 4 (very often) they felt stressed during the last month in relation to the COVID-19 pandemic (Cronbach's $\alpha=0.89$; e.g., in the last month, how often have you felt... difficulties were piling up so high that you could not overcome them?). Instructions prompted participants to respond to each item with reference to feelings of pandemicrelated stress.

\section{Assessing Personality: Actor}

Big Five Inventory The Big Five Inventory (BFI-10; Costa \& McCrae, 1992) was administered to assess trait personality. This short-form, 10-item personality assessment was validated as a concise measure of the Big Five personality traits (e.g., Rammstedt et al., 2013). Instructions were not specific to the COVID-19 pandemic, but rather prompted participants to respond to overarching items about their personalities. Two items measured each of five personality traits: extraversion (e.g., I see myself as someone who...is outgoing, sociable), openness (e.g., ...has an active imagination), conscientiousness (e.g., ...does a thorough job), neuroticism (e.g., ...gets nervous easily), and agreeableness (e.g., ...is generally trusting). Participants rated agreement from 1 (strongly disagree) to 5 (strongly agree). Pearson's Correlations were significant for all 2-item scales (extraversion: $r=52, p<0.001$, agreeableness: $r=0.27, p<0.001$, openness: $r=0.22, p<0.01$, neuroticism: $r=0.47, p<0.001)$ except conscientiousness $(r=0.10>0.05)$. Note that researchers have long debated the appropriate, if any, reliability measure for 2 -item scales (Eisinga et al., 2013). Thus, the reported correlations may underrepresent reliability.

\section{Assessing Personality: Agent}

Resilience The 7-item Brief Resilience Scale (Smith et al., 2008) assessed perceived resilience, that is, adaptation in light of challenging experiences, in relation to the COVID19 pandemic. Agreement to items was rated from 1 (strongly disagree) to 5 (strongly agree; e.g., It does not take me long to recover from a stressful event; Cronbach's $\alpha=0.87$ ).

Locus of Control Participants completed the Measure of Internal-External Control (Rotter, 1966) to indicate their sense of internal versus external control, that is, the extent to which they do or do not expect that they control situations and life experiences. Instructions were not situational to the COVID-19 pandemic. This measure provides a series of thirteen pairs of statements (e.g., trusting fate has never turned out as well for me as making a decision to take a definite course of action vs. I have often found that what is going to happen will happen). For each pair, participants chose the statement they more strongly agreed with (Cronbach's $\alpha=0.40$ ). Higher scores indicated tendency towards more external locus of control, and lower scores indicated tendency towards more internal locus of control. 
Gratitude A modified six-item Gratitude Questionnaire (McCullough et al., 2004) asked participants to rate recent changes in personal gratitude for life as potentially resulting from the onset of the COVID-19 pandemic (e.g., compared to my life before the COVID-19 outbreak, I feel...I have so much in life to be thankful for. Responses were selected with options from 1 (extremely less) to 6 (extremely more, Cronbach's $\alpha=0.84$ ).

\section{Assessing Personality: Author}

Methods for examining the self as author have been debated (e.g., Dunlop et al., 2020). Central tenants of the author level of personality propose that individuals "burnish and synthesize episodic information... into a coherent and integrative life story" (McAdams, 2013, p. 273) that is psychosocially adaptive for the individual. Thus, in the current study, the self as author was measured with respect to the extent of synthesizing a coherent understanding of the COVID-19 pandemic and functional recall of the personal past to navigate challenges introduced by the pandemic.

Integrating the Pandemic Experience The Integration of Stressful Life Experiences Scale (ISLES; Holland et al., 2016) measures the extent to which individuals have developed a coherent and comprehensible understanding of a challenging life event, as well as the extent that they feel solidly grounded in the world around them in light of the challenge. Participants responded to the 17 items included in the ISLES from 1 (strongly disagree) to 5 (strongly agree) to address coherent integration of the COVID-19 pandemic into their life story (e.g., I haven't been able to put the pieces of my life back together since this event; Cronbach's $\alpha=0.89$ ). Scores were reversed such that higher scores indicated more integration of the pandemic.

Functional Recall of the Personal Past The Thinking About Life Experiences Scale (TALE; Bluck \& Alea, 2011) assessed use of memories from one's personal past to navigate the pandemic across three categories of functional use of autobiographical memory. Participants responded from 1 (almost never) to 5 (very frequently) to the 15 -item Scale, indicating how frequently they used personal memory during COVID-19 to serve the functions of self-continuity (e.g., I think about or share memories from my past... when I want to feel that I am the same person that I was before; Cronbach's $\alpha=0.85$ ), directing-behavior (e.g., ... when I believe that thinking about the past can help guide my future; Cronbach's $\alpha=0.87$ ), and social-bonding (e.g., ...when I want to develop a closer relationship with someone; Cronbach's $\alpha=0.85$ ).

\section{Multi-Measurement of Future Outlook in the Wake of the COVID-19 Pandemic}

Life Script Events A modified version of the Life Scripts Events Questionnaire (Berntsen \& Rubin, 2004) measured participants' outlook on a variety of life phase-specific life events that could happen in their upcoming future. Three variables were derived from this measure. Participants first selected whether they expected each event to happen in their future (i.e., number of expected events; $0=$ will not happen; $1=$ will happen; e.g., finding a serious romantic relationship, marriage, having first child, getting engaged, graduating from college, moving out from parents' home, getting a first career-related job, and becoming settled in one's career). The variable describing number of expected events was calculated as a proportion score (i.e., number of anticipated events out of total number of event prompts). For each event anticipated, the participant then rated the valence of expected events from -3 (very negative) to 3 (very positive). Scores for valence of expected events were calculated based on the average valence across all anticipated events. Finally, participants indicated the onset of events, or the year in the future that they thought these events would occur. Scores for the onset of events were calculated based on the average onset of all anticipated life events.

Future Time Perspective The Future Time Perspective Scale (Carstensen \& Lang, 1996) is a widely used assessment of the extent to which individuals see the future as expansive, unlimited, and full of opportunity. Participants rated 10 items from 1 (very untrue) to 7 (very true; e.g., My future is filled with possibilities; Cronbach's $\alpha=0.89$ ).

Prospective Search for Meaning On the Search for Meaning subscale of the Meaning in Life Questionnaire (Steger et al., 2006), participants responded to five items measuring the extent to which they were currently (i.e., past two weeks) searching for meaning in their life. They used a scale from 1 (not at all) to 5 (completely agree; e.g., I have felt that...I am looking for something that makes my life feel meaningful; Cronbach's $\alpha=0.94$ ).

Future Narrative: Emotional Tone Participants were prompted to provide brief narratives concerning their view of their life in the year ahead, in the wake of the COVID-19 pandemic. Two research assistants were reliably trained to code these relatively brief, simple narratives ( $M=94.77$ words) for overall emotional tone as emotionally positive, emotionally negative, or emotionally mixed. A small number of narratives were neutral $(n=13)$ and not coded. Inter-rater reliability was conducted on $15 \%$ of the narratives and found to be acceptable ( $\mathrm{ICC}=0.84$ ). All narratives were then coded for emotional tone by both 
Table 1 Examples of narratives about the year ahead coded for positive, negative, and mixed emotional tone

\begin{tabular}{|c|c|}
\hline Tone & Narrative example \\
\hline Positive & $\begin{array}{l}\text { I see my future as being full of possibilities and hope... I know this is a dark time, but people must remain positive and look for a } \\
\text { bright side. I am sad now that so many activities and events have gotten canceled, but in the future, we must do everything we can to } \\
\text { make the most of these events...I can take actions now, to ensure a brighter future for myself and I look forward to taking opportuni- } \\
\text { ties in the future that I might not have taken in COVID-19 had not happened. My study abroad was canceled for this summer, but I } \\
\text { now want to look for an internship that I can do instead or I can pick up extra hours at the summer job to make more money to have } \\
\text { for school in the fall semester...thinking positively and optimistically helps me remain positive and optimistic now }\end{array}$ \\
\hline Negative & $\begin{array}{l}\text { Looking forward to the next year, I have been scared about what the future holds. I am not coping well with social isolation and doing } \\
\text { school from home, so the idea that this not be over by next fall is scaring me. Quite frankly, if classes are online again in the fall I } \\
\text { might have to switch out of some of my more challenging classes since I do not effectively learn certain topics in an online format. } \\
\text { Then this realization made me start questioning my future, like if I will actually stay on track with my plan to go to med school. } \\
\text { Overall, it's just stressful. I am also sad because I was meant to hang out with my friends that I haven't seen since high school. I had } \\
\text { relatives coming to visit from the UK who I haven't seen in forever, so now I am sad they won't be able to come }\end{array}$ \\
\hline Mixed & $\begin{array}{l}\text { I have been thinking a lot about my future and throughout this time it has changed a lot. Occasionally, I believe I'll have the opportu- } \\
\text { nity to get a job and then other times I don't. I've come to the conclusion that as of my right now my future is very much up in the } \\
\text { air but I have a solid support system that will help me when it comes to it }\end{array}$ \\
\hline
\end{tabular}

Forgers more frequently constructed positive future narratives and less frequently constructed negative future narratives, as reported in Results

coders and any discrepancies were resolved through discussion. Examples of positive, negative, and mixed tone narratives of participants' future outlook on the year ahead appear in Table 1.

\section{Data Analysis Plan}

We first derived the personality compositions, incorporating all personality measures (i.e., pandemic stress; all measures within personality levels of actor, agent, and author) in two analysis methods. In keeping with our theoretical framework, analyses took a person-centered, not variable centered, approach. ${ }^{1}$ In the first set of analyses, to derive personality profiles and address aim 1, both hierarchical cluster analysis (HCA) and latent profile analysis (LPA) were conducted. HCA organizes cases (i.e., participants) into profile clusters based on interrelationships among all variables with the goal of maximizing both inter-group heterogeneity and intragroup homogeneity. The current study used Ward's method with squared Euclidian distances to determine degree of

\footnotetext{
1 This research took a person-centered approach both theoretically and in the analytical plan. That said, readers may be interested in how a variable-centered approach works with these data. We thus conducted exploratory, non-planned, variable-centered analyses. The thirteen personality variables were entered in separate hierarchical regressions, each predicting one of the three (non-life script) future outlook outcome variables. Though $2 / 3$ of these models showed overall significance $\left(R^{2}=0.202-0.345 ; p s<0.001\right)$, few variables emerged as significant predictors within, or across, these regressions. Gratitude was the one personality variable that was of some interest (in predicting future time perspective, $b=0.27, p<0.001$; in predicting bright future outlook, $b=0.50, p=006)$. Overall, the theoretically grounded and planned person-centered approach offered more robust findings. Readers are invited to contact the first author for more information.
}

similarity between the cases. The number of stages in HCA is equal to the number of cases considered with the last stage representing a single-cluster solution. The thirteen personality variables were standardized to ensure that they contributed equally and then were imputed in the HCA. Although no standard guidelines exist for identifying the ideal number of clusters using HCA, locating the first large increase between agglomeration coefficients of successive stages is a well-established, widely used method in the social sciences (Hair et al., 1998).

Given that HCA may be considered an exploratory approach, Latent Profile Analysis (LPA) was then also conducted with the 'tinyLPA' package (Rosenberg et al., 2018) in "R" (R Core Team, 2020). As a data-driven approach, LPA allows users to specify model variances and covariances to either vary, be constrained to be equal, or be constrained to be zero. Allowing for a maximum of a thirteenprofile solution (equal to the number of variables) and testing models in which variances were allowed to vary or be constrained, a total of 52 solutions were tested. Finally, a k-profile solution was selected on the basis of conceptual rationale and the output from the HCA model fit indices traditionally used to assess LPA solutions (AIC, AWE, BIC, CLC, and KIC; Akogul \& Erisoglu, 2017), as well as output from a series of bootstrapping likelihood ratio tests (BLRT; Spurk et al., 2020) which suggest whether the current model, or a model with k-1 profiles better fits the data. As the sample was somewhat underpowered for this analysis (an $\mathrm{N}$ of at least 500 would be sufficient; Nylund et al., 2007), it served to supplement support for the findings from the HCA.

Finally, a series of MANOVA and ANOVA models were used to examine mean level differences in future outlook variables between individuals in each of the two personality compositions. These analyses addressed Aim 2. 
Table 2 Means, standard deviations, group level differences, and discriminant function for variables in the cluster analyses

\begin{tabular}{|c|c|c|c|c|c|c|c|c|}
\hline \multirow[t]{2}{*}{ Variable } & \multicolumn{2}{|c|}{$\begin{array}{l}\text { Reflectors: } \\
\text { profile One } \\
(N=106)\end{array}$} & \multicolumn{2}{|c|}{$\begin{array}{l}\text { Forgers: Profile } \\
\text { two }(N=89)\end{array}$} & \multicolumn{2}{|c|}{ Group differences } & \multicolumn{2}{|c|}{$\begin{array}{l}\text { Discriminant func- } \\
\text { tion }\end{array}$} \\
\hline & $M$ & $S D$ & $M$ & $S D$ & $t$ & $p$ & $d l$ & $s d c$ \\
\hline Extraversion & 2.83 & 1.04 & 3.49 & 0.99 & -4.54 & $<.001$ & 0.260 & 0.213 \\
\hline Agreeableness & 3.46 & 0.87 & 3.97 & 0.70 & -4.47 & $<.001$ & 0.252 & 0.252 \\
\hline Conscientiousness & 3.34 & 0.70 & 3.87 & 0.58 & -5.66 & $<.001$ & 0.320 & 0.372 \\
\hline Openness & 3.71 & 0.91 & 3.44 & 0.95 & 1.92 & 0.06 & -0.111 & -0.438 \\
\hline Neuroticism & 3.82 & 0.90 & 2.78 & 0.88 & 8.17 & $<.001$ & -0.469 & -0.337 \\
\hline Resilience & 2.99 & 0.74 & 3.77 & 0.50 & -8.69 & $<.001$ & 0.485 & 0.382 \\
\hline Locus of Control & 5.80 & 2.15 & 4.72 & 1.88 & 3.75 & $<.001$ & -0.213 & -0.021 \\
\hline Gratitude & 5.03 & 1.03 & 5.45 & 1.05 & -2.80 & .005 & 0.161 & 0.277 \\
\hline Self-continuity & 3.17 & 0.94 & 2.65 & 0.87 & 4.00 & $<.001$ & -0.228 & -0.405 \\
\hline Social-bonding & 3.41 & 0.88 & 3.51 & 0.76 & -0.93 & 0.35 & 0.053 & 0.318 \\
\hline Directing-behavior & 3.64 & 0.86 & 3.65 & 0.73 & -0.05 & 0.96 & 0.003 & 0.132 \\
\hline Perceived stress & 3.23 & 0.47 & 2.55 & 0.61 & 8.50 & $<.001$ & -0.499 & -0.241 \\
\hline Integrating experience & 2.80 & 0.60 & 2.25 & 0.61 & 6.36 & $<.001$ & 0.367 & 0.248 \\
\hline
\end{tabular}

\section{Results}

A hierarchical cluster analysis (HCA) was conducted using the thirteen personality characteristic variables. When exploring the 10-cluster stage through to the single-cluster stage, the consecutive changes in the agglomeration coefficient were $3.27 \%, 3.55 \%, 3.55 \%, 3.63 \%, 3.60 \%, 5.44 \%$, $6.09 \%, 7.82 \%$, and $13.14 \%$. The large noticeable increase between the penultimate and the final stage clearly suggested a two-cluster solution best fits the data. The resultant two profiles were comparable in size $(N=106$ vs $N=89$, see Table 2).

To substantiate the HCA findings presented above, we conducted a latent profile analysis (LPA) using the same thirteen personality characteristics. Using a hierarchical analytic process outlined in Akogul \& Erisoglu, 2017, a 1-profile solution was suggested to best fit the data $(\mathrm{AIC}=6249.39$, $\mathrm{AWE}=7448.18, \mathrm{BIC}=6589.79, \mathrm{CLC}=6043.39$, and $\mathrm{KIC}=6356.39$ ). The next best fitting model was deemed to be a 13-profile solution $(\mathrm{AIC}=6184.67, \mathrm{AWE}=9323.33$, $\mathrm{BIC}=7074.93, \mathrm{CLC}=5642.53$, and $\mathrm{KIC}=6459.68$ ). Lastly, the solution with the third best model fit was a 2-profile solution $(\mathrm{AIC}=6519.27, \mathrm{AWE}=6979.59, \mathrm{BIC}=6650.19$, $\mathrm{CLC}=6440.79, \mathrm{KIC}=6562.27$ ). Due to the absence of information in a 1-profile solution and the difficulty of interpreting a 13-profile solution with 13 variables, the 2-profile solution was the most conceptually parsimonious. Additionally, as suggested by Spurk et al., (2020), we conducted a number of bootstrapped likelihood ratio tests ${ }^{2}$ (BLRT) to

\footnotetext{
$\overline{2}$ Beginning with a single profile solution, this process tests an increasing number of profiles until the solution is no longer significantly improved, which suggests an ideal number of profiles for the data (Spurk et al., 2020).
}

assess the appropriate number of profiles. The results of the BLRT suggested that all of the profile solutions were significantly better than the previous one, offering no additional information regarding the ideal model for the data.

The differences in means among the thirteen variables, across the two clusters using the HCA and the two profiles using LCA, were all in the same direction. Additionally, none of the means derived using the clusters from the HCA or profiles using LCA were significantly different from each other. Based on the consistency between the solution suggested by the cluster analysis and the solution most appropriate from the LPA, the authors decided to use the two-cluster solution from the HCA, including the two-cluster profiles (hereafter discussed as profiles) in the subsequent analyses.

To identify the specific personality characteristics defining the two profiles, a discriminant function analysis (DFA) and squared canonical correlations $\left(\mathrm{R}_{\mathrm{c}}^{2}\right)$ were run. Meanlevel group comparisons were then used to determine relative levels of all variables between profiles. The DFA showed the profiles were strongly differentiated, $\mathrm{R}_{\mathrm{c}}{ }^{2}=0.78$, with $88.2 \%$ of the cases correctly classified and relatively divergent group centroids ( -1.14 and 1.36 , respectively). To interpret the solution based on the DFA, both discriminant loadings (i.e., simple correlations between the predictor variables and scores on the discriminant function) and standardized discriminant coefficients (i.e., partial coefficients indicating the unique contribution of each predictor variable, controlling for the other variables in the discriminant function) were considered. High discriminant loadings $(>0.15)$ combined with high standardized discriminant coefficients $(>0.15)$ were observed (see Table 2). 


\section{Two Personality Profiles}

Two personality profiles were identified from the data and labeled Reflectors (i.e., Profile One) and Forgers (i.e., Profile Two), respectively. These appear to represent different personality types endorsed during the pandemic. Forgers demonstrated more robust, positive personality characteristics across all three levels of McAdams' (2013) personality framework: self as actor, agent, and author. Mean-level comparisons showed that Forgers reported higher conscientiousness, agreeableness, and extraversion (i.e., actor level) relative to Reflectors. In addition, they reported greater resilience, gratitude, and internal locus of control (i.e., agent level) compared to Reflectors. Forgers also reported less COVID-related stress. Reflectors, in contrast, reported higher neuroticism and openness (actor level) as compared to Forgers. They reported lower resilience and gratitude, as well as greater external locus of control (agent level) and described experiencing greater COVID-related stress. Reflectors also reported better integration of the experiences of the pandemic, and higher use of personal memory to maintain self-continuity, as compared to Forgers.

\section{Demonstrating Demographic Similarities Across the Two Profiles}

As a preliminary step, independent $t$ tests and Chi-square tests were conducted to rule out descriptive demographic background variables between the two profiles. This was to ensure that demographic differences were not driving any personality profile-related differences in future outlook. No such issue existed. Reflectors and Forgers did not differ with respect to age, $t(192)=-0.60, p=0.553$, gender, $X^{2}$ $(2)=2.09, p=0.351$, race, $X^{2}(6)=2.30, p=0.897$, religion, $X^{2}(8)=4.35, p=0.824$, political orientation, $X^{2}(3)=4.20$, $p=0.241$, self-rated health, $t(192)=1.68, p=0.094$, or neighborhood characteristics, $X^{2}(2)=0.36, p=0.834$.

\section{Predicting Future Outlook of the Two Personality Profiles}

To examine the extent to which being a Reflector or Forger was related to holding a more positive future outlook, an ANOVA (or MANOVA) approach was taken. Across analyses, profile membership was always entered as the betweengroups variable. As described in detail below, Forgers viewed their future more positively than Reflectors across multiple measures. Chi-square analyses showed that this also held for the emotional tone of the brief narratives that participants shared about views of the year ahead.

\section{Life Script Events}

To examine whether being considered a Reflector or Forger was related to life-phase-relevant life events expected in the upcoming future, a MANOVA was conducted with the three variables related to expected future events entered as dependent variables (i.e., number of expected events, valence of expected events, onset of expected events), $F(1,189)=5.675$, $p=0.001, \eta_{\mathrm{p}}{ }^{2}=0.083 .{ }^{3}$ Follow-up one-way ANOVAs using Pillai's Trace revealed that Forgers expected more future events to occur in their lives $(M=0.96, S D=0.10)$ than Reflectors $(M=0.91, S D=0.18), F(1,189)=4.608$, $p=0.033, \eta_{\mathrm{p}}^{2}=0.024$. Forgers also rated expected future life events as more positive $(M=1.41, S D=0.38)$ than Reflectors $(M=1.72, S D=0.63), F(1,189)=16.253, p<0.001$, $\eta_{\mathrm{p}}{ }^{2}=0.079$. Forgers $(M=25.64, \mathrm{SD}=2.73)$ and Reflectors $(M=26.03, S D=3.52)$ did not differ on the onset of expected future events.

\section{Future Time Perspective}

A one-way ANOVA indicated that Forgers $(M=5.57$, $S D=0.90)$ reported having a more expansive, positive future time perspective than Reflectors $(M=4.92, S D=1.07)$, $F(1,191)=20.033, p<0.001, \eta_{\mathrm{p}}^{2}=0.095$.

\section{Prospective Search for Life's Meaning}

A one-way ANOVA showed that Reflectors $(M=3.46$, $S D=1.24)$ reported searching more for meaning to make sense of the life that lies ahead of them, as compared to Forgers $(M=3.03, S D=1.13), F(1,192)=6.022, p=0.15$, $\eta_{\mathrm{p}}{ }^{2}=0.030$.

\section{Emotional Tone: Brief Narratives of the Year Ahead}

Based on content coding (i.e., positive, negative, mixed tone) of brief narratives regarding the year ahead, chisquare analysis, $X^{2}(2)=11.66, p=0.003$, showed that Forgers narrated the coming year positively at greater than expected value (positive: observed $=49 /$ expected $=38.9$ ) and narrated with both a negative and mixed tone at less than expected values (negative: observed $=17 /$ expected $=26.5$, mixed: observed $=8 /$ expected $=9.6$ ). In contrast, Reflectors narrated the year ahead with a negative or mixed tone more often than expected value (negative: count $=41 / \exp$ count $=31.5$; mixed: count $=13 /$ exp count $=11.4)$ and with

\footnotetext{
${ }^{3}$ Note, since the Box's Test of Equality of Covariance Matrices in the MANOVA was significant, results are reported based on the Pillai's Trace, a more conservative test.
} 
a positive tone less often than expected (positive: count $=36$ / exp count $=46.1$ ).

\section{Discussion}

Emerging adults have faced many life challenges due to the COVID-19 pandemic (Kassid, 2020). We postulated that these challenges may dampen their future outlook on life in this crucial developmental period. We examined whether emerging adults showed distinct personality profiles and whether these were linked with having a positive outlook on their future, even in the midst of the COVID-19 pandemic. Findings showed that despite being demographically similar, emerging adults deemed as Forgers demonstrated robust personality characteristics across multiple levels of personality (McAdams, 2013). This included lower COVID19-related stress, indicative of psychologically 'pushing forward' through pandemic-related challenges, or otherwise separating the self from current or future pandemic-related concerns. Indeed, holding this personality was related to a brighter outlook on the future in the midst of the early pandemic, as compared to Reflectors. Maintaining a positive view of one's future in the face of such challenges may be crucial in promoting constructive goal-setting and psychosocial growth in this life phase, thereby fostering a smooth transition to adulthood. In contrast, emerging adults deemed as Reflectors exhibited more pandemic reactivity, including higher stress but also more psychological integration of the pandemic experience into their sense of self. In other words, those with this personality appeared to have immersed themselves more fully in the reality of the pandemic as it began, acknowledging real or possible effects of the pandemic as it first unfolded. Reflectors' personality was related to holding a somewhat bleaker future outlook than Forgers.

\section{Emerging Adults' Personality Profiles: Adapting to the COVID-19 Pandemic}

Across multiple levels of personality (i.e., actor, agent, author; McAdams, 2013), Forgers showed a set of personality characteristics likely to buoy them psychologically considering the difficult circumstances of the pandemic. In contrast, Reflectors demonstrated personality traits which instead appeared more reactive to early felt or expected strains of the pandemic. These differences in the two profiles may reflect differing abilities to remain future-oriented considering the rapidly evolving challenges of the pandemic. As such, the differences in the two profiles may represent varying abilities to adapt during other similarly challenging major national or global events, including longer-term consequences of the pandemic.
As actors (McAdams, 2013), Forgers endorsed robust personality traits (Costa \& McCrae, 1992) including higher extraversion, agreeableness, and conscientiousness than Reflectors. This is a desired personality composition in relation to fulfilling tasks that will aid the transition to adulthood (Roberts et al., 2005). Such traits are associated with longterm subjective well-being and adaptive functioning (e.g., Richards \& Huppert, 2011). As such, this personality profile is likely well suited for navigating the changes, setbacks, and uncertainty of the COVID-19 pandemic. Reflectors, in contrast, rated themselves as close to neutral, on average, on the socially desirable personality traits and, instead, showed higher neuroticism and openness than Forgers. Higher neuroticism is consistent with experiencing worry, fear, and frustration (Costa \& McCrae, 1992). Neuroticism has been related to negative long-term implications for subjective well-being (Steele et al., 2008). Reflectors, with neuroticism as a prominent aspect of their profile, may be more vulnerable to feelings of worry and insecurity as they experience life during the pandemic.

As agents (McAdams, 2013), Forgers reported greater resilience in relation to the COVID-19 pandemic than Reflectors, showing the capability to adapt nimbly to difficulty (Masten, 2001; Smith et al., 2008). Forgers, compared to Reflectors, also reported enhanced gratitude (McCullough et al., 2004) from experiencing the pandemic. Gratitude can act as a psychosocial resource for mental health in dealing with life changes (e.g., Bohlmeijer et al., 2020). Gratitude involves recognition of simple pleasures and abundance, even in the face of loss. In fact, self-care practices promoted during the pandemic include daily recognition of what one feels grateful for (Fessell \& Cherniss, 2020). Bono and colleagues (2020) further demonstrate that emerging adults, in particular, are benefiting from gratitude during the pandemic. In sum, Forgers appear to show a robust agentlevel personality through a combination of resilience and enhanced gratitude.

As authors (McAdams, 2013) across late adolescence, individuals are forming their identity as a biographical life story (Habermas \& Bluck, 2000) and integrating new, sometimes challenging life events (Bluck \& Alea, 2011). Emerging adults deemed as Reflectors might be struggling to author a life story in which the self feels coherent because they reported using personal memories during the pandemic more often than Forgers to maintain or rebuild their feelings of self-continuity. This is supported by research showing that younger adults who report having a less clear sense of self-concept (Campbell et al., 1996) more frequently reflect on their personal past in an effort to forge self-continuity (i.e., as compared to older people; Bluck \& Alea, 2008). Yet, Reflectors tended to integrate the pandemic more with their life story relative to Forgers. That is, Reflectors appeared to be more sensitive, and possibly more realistic, to the major 
ways in which the pandemic could impact them and their future lives. As such, their greater integration of the pandemic into their current life story may allow them to engage in more health-positive behaviors that could potentially guide them as they navigate this unique and challenging global health crisis. Ultimately, whether this sensitivity at the author level will be helpful or harmful as the pandemic continues to disturb its youth will be of relevance for a future study.

\section{Different Personality Profiles: Varying Outlooks on the Future}

A major focus of this work was to identify whether personality might, to differing extents, aid in having a bright outlook on one's future in the face of the pandemic. Forgers demonstrated a more positive future outlook than Reflectors across multiple assessments. That is, they expected more positive life events related to transitioning into adulthood to occur in their future (e.g., first job, settle on a career, romantic partner) compared to individuals who were Reflectors. Forgers also reported, compared to Reflectors, a more positive, open time frame for their future life overall. Reflectors, in contrast, felt more need to search for meaning in the life ahead and, in open-ended narratives, more frequently had a negative emotional tone in talking about the year ahead.

Though this research is cross-sectional, results could be interpreted to suggest that individuals' divergent outlooks on their future during the COVID-19 pandemic are rooted in personality. As actors and agents, Forgers perceived themselves as robust and resourceful individuals who overcome life obstacles relatively easily. This personality profile (Masten, 2001; Smith et al., 2008) may allow for more readily maintaining an expansive outlook on one's future despite the negative consequences of the pandemic, at least for a time. That is, Forgers may interpret COVID-19 as a challenge that can be managed or avoided. The sense of gratitude inherent to Forgers may also foster faith that, if they can appreciate life today, they will be able to do so in the future. For example, some individuals expressed in their future narratives having positively shifted priorities to people and activities that they wished they had time for pre-pandemic. Similarly, Shanahan and colleagues (2020) have shown that positive reappraisal is related to reduced distress during COVID-19. Forgers provided more positive brief narratives of what the year ahead would hold: that the future may be different but can still be bright.

Emerging adults who were characterized as Reflectors evidenced more stress in relation to the pandemic than Forgers, despite no perceived health differences (i.e., their stress was not related to actually contracting COVID-19). We speculate that their ruminative tendencies (i.e., higher neuroticism) may be associated with their holding a somewhat bleaker future outlook, including feeling greater stress about the ongoing challenges associated with the pandemic. This tendency was also reflected in their view of themselves as less able to overcome challenges (i.e., reported lower resilience). Their lower resilience may be manifesting in their expectation that their future will contain fewer, and less positive, completion of normative milestones (e.g., settle on an occupation, establish a family). Their year ahead was also narrated as less manageable, again reflecting lower resilience in the context of the pandemic (e.g., not coping well with social isolation and completing classes from home; see narrative examples, Table 1). Although this outlook may be more realistic in retrospect, considering the difficulties faced in this multi-year pandemic, to hold such an outlook at the onset of the pandemic may have more quickly led to life disruption, feelings of hopelessness, or unmanaged anxiety about the present and future in this profile of emerging adults. Future research should examine the ways that each of these personality profiles, and related future outlooks, assist in or hinder navigation of long-term pandemic hardship.

\section{Fostering Resilience During the Transition to Adulthood}

Forgers represent emerging adults who, supported by their personality, are able to uphold a positive future outlook in the midst of pandemic-related obstacles. Despite sometimes critical views on the current generation's ability to handle challenges (e.g., Trzesniewski \& Donnellan, 2014), these individuals responded with resourcefulness. Reflectors, on the other hand, embody a somewhat different style of coping. They may, understandably given the many challenges of the pandemic, be in need of external resources and support. One example of such support would be to actively foster struggling emerging adults' resilience and gratitude. As the COVID-19 pandemic continues, this may help them maintain, or regain, a more positive view of their future. There is some initial evidence that these malleable aspects of personality boost positive affect and buffer against external, pandemic-related stressors (e.g., Jian 2020; Kavčič et al., 2021). Institutional support could focus on helping these young people learn the skills needed to adaptively integrate current pandemic experiences into their continuing life story that is emerging in adolescence-to tell a story in which developmental goals may be delayed or manifest differently but can still be achievable. Thus, organizations might consider making external resources available as part of the ecology of emerging adults' daily life (e.g., through university counseling center programs, peer-led support groups, education modules posted on social media platforms). That said, we are cautious to note that the current study does not provide causal links between personality profiles, or individual variables, and positive future outlook. As such, any such 
intervention or institutional support awaits replication with a design that shows causal relations. Though such resources may be useful, it is also important to note that the study findings suggest that the majority of emerging adults reported adapting well to the onset of the pandemic.

\section{Limitations}

Some limitations should be noted. First, as the goal of the study was to describe personality compositions in relation to future outlook, we focused on self-perceptions and self-reports and did not assess what might be considered objective assessments (e.g., number of stressful life events during the pandemic). It is thus unknown whether Forgers and Reflectors differ on stressful life events that occurred at the onset of the pandemic, that aside from their personality, might be related to their future outlook. In addition, although the differences between Forgers and Reflectors were clear and consistent, this was a university student sample so findings may not be generalizable to other emerging adults. In terms of measurement issues, the reliability statistic for the locus of control variable was notably low. Locus of control is a crucial component of operationalizing levels of personality, particularly in reference to historical or environmental contexts, and has been assessed in multiple recent COVID19 studies (Krampe et al., 2021; Lu \& Wang, 2021; Tagini et al., 2021), so was retained in analyses despite the low reliability statistic. The influence of locus of control as a defining feature of the agent level of personality, and as a predictor of future outlook in this context, should be interpreted with caution.

\section{Conclusion}

This research identified distinct profiles of personality among emerging adults and investigated how these profiles were related to individuals' outlook on their future at the onset of the COVID-19 pandemic. Two personality profiles were identified. Emerging adults deemed Forgers were characterized by having more robust personalities and this was related to having a more positive, expansive outlook on the future in the midst of COVID-19. In contrast, emerging adults deemed Reflectors showed a somewhat bleaker, but perhaps more realistic, view of what the future might hold. Knowledge about adaptive personality types may eventually be used to help communities and health care workers tailor support to emerging adults as they transition into the future, into adulthood, while continuing to cope with the ongoing challenges of COVID-19.
Acknowledgements We would like to thank William L. Dunlop for his guidance with our analyses.

Funding Dr Lind is funded by The Independent Research Fund Denmark (No. 8023-00029B); Dr. Mroz is supported by NIA Institutional Training Grant: T32AG019134.

Data Availability Data and study material are available upon request.

\section{Declarations}

Conflict of interest The authors declare no conflict of interest.

\section{References}

Akogul, S., \& Erisoglu, M. (2017). An approach for determining the number of clusters in a model-based cluster analysis. Entropy, 19(9), 452.

Andre, L., van Vianen, A. E. M., Peetsma, T. T. D., \& Oort, F. J. (2018). Motivational power of future time perspective: Metaanalyses in education, work, and health. PLoS ONE, 13(1), 45. https://doi.org/10.1371/journal.pone.0190492

Arnett, J. J. (2007). Emerging adulthood: What is it, and what it is good for? Child Development Perspectives, 1(2), 68-73. https://doi.org/ 10.1111/j.1750-8606.2007.00016.x

Arnett, J. J. (2013). The evidence for generation we and against generation me. Emerging Adulthood, 1(1), 5-10. https://doi.org/10.1177/ 2F2167696812466842

Baltes, P. B. (1997). On the incomplete architecture of human ontogeny: Selection, optimization, and compensation as foundation of developmental theory. American Psychologist, 52(4), 366-380. https://doi.org/10.1037/0003-066X.52.4.366

Berntsen, D., \& Rubin, D. C. (2004). Cultural life scripts structure recall from autobiographical memory. Memory \& Cognition, 32(3), 427-442. https://doi.org/10.3758/bf03195836

Bluck, S., \& Alea, N. (2008). Remembering being me: The self continuity function of autobiographical memory in younger and older adults. In F. Sani (Ed.), Self continuity: Individual and collective perspectives (pp. 55-70). Psychology Press.

Bluck, S., \& Alea, N. (2011). Crafting the TALE: Construction of a measure to assess the functions of autobiographical remembering. Memory, 19(5), 470-486. https://doi.org/10.1080/09658211. 2011.590500

Bohlmeijer, E. T., Kraiss, J. T., Watkins, P., \& Schotanus-Dijkstra, M. (2020). Promoting Gratitude as a Resource for Sustainable Mental Health: Results of a 3-Armed Randomized Controlled Trial up to 6 Months Follow-up. Journal of Happiness Studies, 1-22.

Bono, G., Reil, K., \& Hescox, J. (2020). Stress and wellbeing in urban college students in the US during the COVID-19 pandemic: Can grit and gratitude help? International Journal of Wellbeing. https://doi.org/10.5502/ijw.v10i3.1331

Campbell, J. D., Trapnell, P. D., Heine, S. J., Katz, I. M., Lavallee, L. F., \& Lehman, D. R. (1996). Self-concept clarity: Measurement, personality correlates, and cultural boundaries. Journal of Personality and Social Psychology, 70(1), 141-156. https://doi.org/ 10.1037/0022-3514.70.1.141

Campbell, A. D. (2020). Practical implications of physical distancing, social isolation, and reduced physicality for older adults in response to COVID-19. Journal of Gerontological Social Work, 63, 668-670. https://www.tandfonline.com/loi/wger20 
Carstensen, L. L., Isaacowitz, D. M., \& Charles, S. T. (1999). Taking time seriously: A theory of socioemotional selectivity. American psychologist, 54(3), 165.

Carstensen, L. L., \& Lang, F. R. (1996). Future Orientation Scale. Unpublished manuscript, Stanford University.

Carstensen, L. L., Shavit, Y. Z., \& Barnes, J. T. (2020). Age advantages in emotional experience persist even under threat from the COVID-19 pandemic. Psychological Science, 31(11), 1374 1385. https://doi.org/10.1177/2F0956797620967261

Centers for Disease Control and Prevention (2020). Use Masks to Slow the Spread of COVID-19. https://www.cdc.gov/coronavirus/2019-ncov/prevent-getting-sick/masks.html?CDC_AA_ refVal=https $\% 3 \mathrm{~A} \% 2 \mathrm{~F} \% 2 \mathrm{Fwww} . \mathrm{cdc}$.gov $\% 2 \mathrm{Fcoronavirus} \%$ 2F2019-ncov\%2Fprevent-getting-sick\%2Fdiy-cloth-face-cover ings.html

Cohen, S., Kamarck, T., \& Mermelstein, R. (1983). A global measure of perceived stress. Journal of Health and Social Behavior, 24(4), 385-396. https://doi.org/10.2307/2136404

Cohn, D'Vera (2020) About a fifth of adults in the US have moved due to COVID-19 or know someone who did, a new study shows. FACTANK. https://www.pewresearch.org/fact-tank/2020/07/06/ about-a-fifth-of-u-s-adults-moved-due-to-covid-19-or-knowsomeone-who-did/

Costa, P. T., \& McCrae, R. R. (1992). Normal personality assessment in clinical practice: The NEO Personality Inventory. Psychological Assessment, 4(1), 5-13. https://doi.org/10.1037/1040-3590.4.1.5

Costa, P. T., Jr., McCrae, R. R., \& Lockenhoff, C. E. (2019). Personality across the life span. Annual Review of Psychology, 70, 423-448. https://doi.org/10.1146/annurev-psych-010418-103244

Demiray, B., \& Bluck, S. (2014). Time since birth and time left to live: Opposing forces in constructing psychological wellbeing. Ageing \& Society, 34(7), 1193-1218. https://doi.org/10.1017/S0144 686X13000032

Dunlop, W. L. (2015). Contextualized personality, beyond traits. European Journal of Personality, 29(3), 310-325. https://doi.org/10. 1002/per.1995

Dunlop, W. L., Harake, N., Wilkinson, D., \& Graham, L. (2020). On rhetoric and ratings: Assessing narrative identity via conceptual coding and self-ratings. Journal of Research on Personality. https://doi.org/10.1016/j.jrp.2020.103922

Eisinga, R., \& Grotenhuis, M. (2013). The reliability of a two-item scale: Pearson, cronbach, or spearman-brown? International Journal of Public Health, 58(4), 637-642. https://doi.org/10.1007/ s00038-012-0416-3

Erikson, E. H. (1968). Identity: Youth and crisis (No. 7). WW Norton $\&$ company.

Fessell, D., \& Cherniss, C. (2020). Coronavirus disease 2019 (COVID19) and beyond: micropractices for burnout prevention and emotional wellness. Journal of the American College of Radiology: JACR, 17(6), 746-748. https://doi.org/10.1016/j.jacr.2020.03.013

Florida Department of Health. (2020, March 30). Florida Department of Health updates new COVID-19 cases, announces three new deaths related to COVID-19, morning update. Florida Health, online. http://www.floridahealth.gov/newsroom/2020/03/0330201100-covid19.pr.html

Gonzalez-Sanguino, C., Ausin, B., Castellanos, M. A., Saiz, J., LopezGomez, L., Ugidos, C., \& Munoz, M. (2020). Mental health consequences during the initial stage of the 2020 Coronavirus pandemic (COVID-19) in Spain. Brain, Behavior, and Immunity, 87, 172-176. https://doi.org/10.1016/j.bbi.2020.05.040

Habermas, T., \& Bluck, S. (2000). Getting a life: The emergence of the life story in adolescence. Psychological Bulletin, 126(5), 748-769. https://doi.org/10.1037/0033-2909.126.5.748

Hair, J. F., Anderson, R. E., Tatham, R. L., \& Black, W. C. (1998). Multivariate Data Analysis (5th ed.). Prentice-Hall.
Holland, J. M. (2016). Integration of Stressful Life Experiences Scale (ISLES). In R. A. Neimeyer (Ed.), Series in death, dying, and bereavement. Techniques of grief therapy: Assessment and intervention (p. 46-50). Routledge/Taylor \& Francis Group.

Jiang, D. (2020) Feeling gratitude is associated with better well-being across the life span: a daily diary study during the COVID-19 outbreak. The Journals of Gerontology: Series B.

Kassid, S. (2020) What about us? Youth (un)employment in times of COVID-19. World Future Council. https://www.worldfuturecoun cil.org/covid19-what-about-us/

Kavčič, T., Avsec, A., \& Kocjan, G. Z. (2021). Psychological functioning of Slovene adults during the COVID-19 pandemic: Does resilience matter? Psychiatric Quarterly, 92, 207-216.

Krampe, H., Danbolt, L. J., Haver, A., Stålsett, G., \& Schnell, T. (2021). Locus of control moderates the association of COVID-19 stress and general mental distress: Results of a Norwegian and a German-speaking cross-sectional survey. BMC Psychiatry, 21(1), 1-13. https://doi.org/10.1186/s12888-021-03418-5

Lind, M., Bluck, S., \& McAdams, D. P. (2020). More Vulnerable? The Life story approach highlights older people's' potential for strength during the pandemic. The Journals of Gerontology. https://doi.org/10.1093/geronb/gbaa105

Lu, Y., \& Wang, C. (2021). Asian Americans' racial discrimination experiences during COVID-19: Social support and locus of control as moderators. Asian American Journal of Psychology. https:// doi.org/10.1037/aap0000247

Luchetti, M., Lee, J. H., Aschwanden, D., Sesker, A., Strickhouser, J. E., Terracciano, A., \& Sutin, A. R. (2020). The trajectory of loneliness in response to COVID-19. American Psychologist. https:// doi.org/10.1037/amp0000690

Luthar, S. S. (2006). Resilience in development: A synthesis of research across five decades. Cicchetti, D \& Cohen, D. J. (Eds.), Developmental Psychopathology: Risk, Disorder, and Adaptation, Volume 3 ( $2^{\text {nd }}$ edition). New York: Wiley

Masten, A. S. (2001). Ordinary magic: Resilience processes in development. American psychologist, 56(3), 227.

McAdams, D. P. (2013). The psychological self as actor, agent, and author. Perspectives on Psychological Science, 8(3), 272-295. https://doi.org/10.1177/2F1745691612464657

McCullough, M. E., Tsang, J., \& Emmons, R. A. (2004). Gratitude in intermediate affective terrain: Links of grateful moods to individual differences and daily emotional experience. Journal of Personality and Social Psychology, 86(2), 295-309. https://doi. org/10.1037/0022-3514.86.2.295

Neff, K. D., \& McGehee, P. (2010). Self-compassion and psychological resilience among adolescents and young adults. Self and Identity, 9(3), 225-240. https://doi.org/10.1080/15298860902979307

Nurmi, J.-E. (2005). Thinking About and Acting Upon the Future: Development of Future Orientation Across the Life Span. In A. Strathman \& J. Joireman (Eds.), Understanding behavior in the context of time: Theory, research, and application (pp. 31-57). Lawrence Erlbaum Associates Publishers.

Nylund, K. L., Asparouhov, T., \& Muthén, B. O. (2007). Deciding on the number of classes in latent class analysis and growth mixture modeling: A Monte Carlo simulation study. Structural Equation Modeling: A Multidisciplinary Journal, 14(4), 535-569. https:// doi.org/10.1080/10705510701575396

Pohle, A. (2020). How the coronavirus has affected family planning. The Wall Street Journal. https://www.wsj.com/articles/how-thecoronavirus-has-affected-family-planning-11593543743

Prime, H., Wade, M., \& Browne, D. T. (2020). Risk and resilience in family well-being during the COVID-19 pandemic. American Psychologist, 75(5), 631-643. https://doi.org/10.1037/amp00 00660 
R Core Team (2020). R: A language and environment for statistical computing. R Foundation for Statistical Computing, Vienna, Austria. URL https://www.R-project.org/.

Rammstedt, B., Kemper, C. J., Klein, M. C., Beierlein, C., \& Kovaleva, A. (2013). A short scale for assessing the big five dimensions of personality: 10 item big five inventory (BFI-10). Methods, Data, Analyses, 7(2), 17. https://doi.org/10.12758/mda.2013.013

Richards, M., \& Huppert, F. A. (2011). Do positive children become positive adults? Evidence from a longitudinal birth cohort study. The Journal of Positive Psychology, 6(1), 75-87. https://doi.org/ 10.1080/17439760.2011.536655

Roberts, B. W., Wood, D., \& Smith, J. L. (2005). Evaluating Five Factor Theory and social investment perspectives on personality trait development. Journal of Research in Personality, 39(1), 166-184. https://doi.org/10.1016/j.jrp.2004.08.002

Rosenberg, J. M., Beymer, P. N., Anderson, D. J., Van Lissa, C. J., \& Schmidt, J. A. (2018). tidyLPA: An R package to easily carry out latent profile Analysis (LPA) using open-source or commercial software. Journal of Open Source Software, 3(30), 978. https:// doi.org/10.21105/joss.00978

Rotter, J. B. (1966). Generalized expectancies for internal versus external control of reinforcement. Psychological Monographs: General and Applied, 80(1), 1-28. https://doi.org/10.1037/h0092976

Segran, E. (2020). Love, delayed. As the pandemic rages on, single people are feeling the anxiety of missed opportunities. Vox. https://www.vox.com/the-highlight/21550996/dating-love-coron avirus-covid-19-singles-relationships

Shanahan, L., Steinhoff, A., Bechtiger, L., Murray, A. L., Nivette, A., Hepp, U., Ribeaud, D., \& Eisner, M. (2020). Emotional distress in young adults during the COVID-19 pandemic: Evidence of risk and resilience from a longitudinal cohort study. Psychological Medicine. https://doi.org/10.1017/S003329172000241X

Smith, B. W., Dalen, J., Wiggins, K., Tooley, E., Christopher, P., \& Bernard, J. (2008). The brief resilience scale: Assessing the ability to bounce back. International Journal of Behavioral Medicine, 15(3), 194-200. https://doi.org/10.1080/10705500802222972

Spurk, D., Hirschi, A., Wang, M., Valero, D., \& Kauffeld, S. (2020). Latent profile analysis: A review and "how to" guide of its application within vocational behavior research. Journal of Vocational Behavior, 120, 1-21.

Steel, P., Schmidt, J., \& Shultz, J. (2008). Refining the relationship between personality and subjective well-being. Psychological Bulletin, 134, 138-161. https://doi.org/10.1037/0033-2909.134.1.138
Steger, M. F., Frazier, P., Oishi, S., \& Kaler, M. (2006). The meaning in life questionnaire: Assessing the presence of and search for meaning in life. Journal of Counseling Psychology, 53(1), 80-93. https://doi.org/10.1037/0022-0167.53.1.80

Sulimani-Aidan, Y. (2015). Do they get what they expect?: The connection between young adults' future expectations before leaving care and outcomes after leaving care. Children and Youth Services Review, 55, 193-200. https://doi.org/10.1016/j.childyouth.2015. 06.006

Tagini, S., Brugnera, A., Ferrucci, R., Mazzocco, K., Pievani, L., Priori, A., \& Poletti, B. (2021). Attachment, personality and locus of control: psychological determinants of risk perception and preventive behaviors for COVID-19. Frontiers in Psychology, 12, 1-12. https://doi.org/10.3389/fpsyg.2021.634012

Tidey, A. (2020). COVID-19 creating 'lockdown generation'as young workers rake the biggest hit. Euronews. https://www.euronews. com/2020/05/28

Trzesniewski, K. H., \& Donnellan, M. B. (2014). "Young People These Days..." evidence for negative perceptions of emerging adults. Emerging Adulthood, 2(3), 211-226. https://doi.org/10.1177/ 2167696814522620

Wang, C., Pan, R., Wan, X., Tan, Y., Xu, L., Ho, C. S., \& Ho, R. C. (2020). Immediate psychological responses and associated factors during the initial stage of the 2019 coronavirus disease (COVID-19) epidemic among the general population in China. International Journal of Environmental Research and Public Health, 17(5), 1729.

World Health Organization (2020). Coronavirus Disease 2019 (COVID-19) (Situation Report No. 67). chrome-extension:// efaidnbmnnnibpcajpcglclefindmkaj/viewer.html?pdfurl=https\% $3 \mathrm{~A} \% 2 \mathrm{~F} \% 2 \mathrm{Fw} w w . w h o . i n t / 2 \mathrm{Fdocs} / 2 \mathrm{Fdefault}$-source/2Fcoronavi ruse/2Fsituation-reports/2F20200327-sitrep-67-covid-19.pdf/ 3Fsfvrsn/3Db65f68eb_4\&clen $=1203370 \&$ chunk $=$ true

Zhang, L. (2020). COVID-19 leads to dramatic unemployment, young people suffer the most, CGTN. https://news.cgtn.com/news/202005-29/COVID-19-leads-to-dramatic-unemployment-young-people-suffer-the-most-QSUcPNPJ0Q/index.html

Publisher's Note Springer Nature remains neutral with regard to jurisdictional claims in published maps and institutional affiliations. 